\title{
Ler Fanon no século XXI
}

Reading Fanon in the Twenty-first Century

Lire Fanon au XXIème siècle

\section{Immanuel Wallerstein}

Tradutor: António Sousa Ribeiro

\section{OpenEdition}

\section{Journals}

\section{Edição electrónica}

URL: http://journals.openedition.org/rccs/611

DOI: $10.4000 /$ rccs. 611

ISSN: 2182-7435

\section{Editora}

Centro de Estudos Sociais da Universidade de Coimbra

Edição impressa

Data de publição: 1 Setembro 2008

Paginação: 3-12

ISSN: 0254-1106

\section{Refêrencia eletrónica}

Immanuel Wallerstein, «Ler Fanon no século XXI », Revista Crítica de Ciências Sociais [Online]

82 | 2008, colocado online no dia 01 dezembro 2012, criado a 19 abril 2019. URL : http:// journals.openedition.org/rccs/611; DOI : 10.4000/rccs.611 


\section{IMMANUEL WALLERSTEIN}

\section{Ler Fanon no século XXI}

Discute-se a actualidade do pensamento de Frantz Fanon, em torno de três eixos principais que constituem outros tantos dilemas - o uso da violência, a afirmação da identidade e a luta de classes -, demonstrando como, no tempo presente, estas questões continuam a ser decisivas na luta por um sistema-mundo mais justo e solidário.

Frantz Fanon nasceu na Martinica, em 1925, e morreu de leucemia, demasiado novo, em 1961. Em 1952, já médico e psiquiatra, publicou o seu primeiro livro, Peau noire, masques blancs. Trata-se de uma obra notável, que teve algum impacto nos círculos intelectuais da França da altura. Era um cri de coeur apaixonado a exprimir a sua "experiência de um homem negro mergulhado num mundo branco", palavras que Francis Jeanson, autor do prefácio, usou para sintetizar o tema do livro.

Fanon diz na introdução que superar a alienação do homem negro exigiria mais do que era proporcionado por Freud. Freud tinha defendido a necessidade de passar de uma explicação filogenética a uma explicação ontogenética, mas, de acordo com Fanon, o que era necessário era uma explicação sociogénica, mesmo se reconhecia as limitações deste tipo de explicação, recordando ao leitor: "pertenço irredutivelmente à minha época" (Fanon, 1971: 10).

A época de Fanon eram os anos cinquenta. O livro teve uma segunda vida em inglês trinta anos depois, altura em que se transformou num texto central do cânone pós-moderno. Mas ele não era de modo nenhum um apelo a uma política de identidade. Muito pelo contrário. Na página final do livro o autor faz uma declaração muito clara das razões por que não deve seguir-se uma tal política:

A desgraça do homem de cor é ter sido escravizado.

A desgraça e a inumanidade do branco são ter morto o ser humano algures.

São, ainda hoje, o facto de organizar racionalmente esta desumanização. Mas eu, o homem de cor, na medida em que se me torna impossível existir absolutamente, não tenho o direito de me acantonar num mundo de reparações retroactivas. 
Eu, o homem de cor, quero apenas uma coisa:

Que jamais o instrumento domine o ser humano. Que cesse para sempre a subjugação do homem pelo homem. Quer dizer, de mim por um outro. Que me seja permitido descobrir e querer o ser humano onde quer que ele se encontre.

O negro não existe. Tal como o branco não existe. (Fanon, 1971: 187)

Em França, onde o autor vivia na época, os anos cinquenta foram dominados pela guerra de independência da Argélia, que começou em 1954 e terminou em 1962, um ano após a morte de Fanon. Em 1953, ele foi nomeado director de serviço de psiquiatria no hospital de Blida, na Argélia. Não tardou a sentir-se revoltado com as histórias de torturas que os seus doentes argelinos the contavam. Sendo já um simpatizante da causa argelina, demitiu-se do seu lugar e foi para a Tunísia para trabalhar a tempo inteiro para o Gouvernement Provisoire de la Révolution Algérienne (GPRA). Escreveu inúmeros textos para El Moudjahid, o jornal oficial da revolução. Em 1960, o GPRA enviou-o como embaixador para o Gana, que, naqueles anos, era o centro efectivo do movimento para a unidade africana. Foi em Accra, no Gana, que me encontrei com ele em 1960 e foi aí que tivemos longas discussões sobre a situação política mundial.

Fanon adoeceu de leucemia e foi primeiro para a União Soviética e, depois, para os Estados Unidos para se submeter a tratamentos que se revelaram infrutíferos. Pude conversar com ele no hospital, onde tivemos discussões centradas no movimento dos Panteras Negras que estava a nascer nos Estados Unidos e com o qual ele estava fascinado. No seu último ano de vida, ele dedicou-se principalmente e com toda a fúria a escrever o livro que foi publicado postumamente como Les damnés de la terre. O livro traz um prefácio famoso da autoria de Jean-Paul Sartre, que Fanon achava brilhante. O título, evidentemente, era tirado do primeiro verso da Internacional, o hino do movimento operário mundial.

Foi este livro, e não o primeiro, que granjeou a Fanon uma reputação mundial, incluindo, é claro, nos Estados Unidos. O livro tornou-se quase uma bíblia para todos os que estavam envolvidos nos muitos e diversos movimentos que culminaram na revolução mundial de 1968. Depois de as labaredas de 1968 se terem extinguido, a obra de Fanon retirou-se para um canto menos turbulento. E, no final dos anos oitenta, os vários movimentos identitários e pós-coloniais descobriram o primeiro livro, a que prodigalizaram a sua atenção, em grande parte sem entenderem o que Fanon queria dizer com ele. Fosse o que fosse que Fanon era, ele não era um pós-modernista. Em vez disso, podia ser caracterizado como tendo uma parte de freudiano marxista, uma parte de marxista freudiano e, no 
fundamental, como estando inteiramente empenhado em movimentos revolucionários de libertação.

A última frase de Peau noire, masques blancs é a seguinte: "A minha última prece: ó meu corpo, faz de mim sempre um homem que interroga!” (Fanon: 1971: 188). É neste espírito de interrogação que apresento as minhas reflexões sobre a utilidade do pensamento de Fanon para o século XXI.

Ao reler os seus livros, há duas coisas que me chamam a atenção: a primeira é a medida em que fazem declarações muito altissonantes em relação às quais Fanon parece muito seguro, sobretudo quando está a ser crítico no tocante a outros. A segunda é que estas declarações são normalmente seguidas, por vezes muitas páginas adiante, pela formulação por Fanon das suas incertezas sobre a melhor maneira de continuar, sobre o modo como se pode conseguir o que tem de conseguir-se.

Também me chama a atenção, como chamou a Sartre, o grau em que estes livros não se dirigem de modo nenhum aos poderosos do mundo, mas antes aos "condenados da terra", uma categoria que, para o autor, é largamente coincidente com "as pessoas de cor". Fanon está sempre enfurecido com os poderosos, que são, ao mesmo tempo, cruéis e condescendentes. Mas está ainda mais enfurecido com as pessoas de cor cujo comportamento e atitudes contribuem para manter o mundo de desigualdades e de humilhação e que, muitas vezes, se comportam assim apenas para obter umas migalhas para si próprias.

Irei organizar as minhas reflexões em torno do que julgo serem três dilemas para Fanon: o uso da violência, a afirmação da identidade e a luta de classes.

O que deu a Les damnés de la terre tanta força e atraiu tanta atenção - admirativa e condenatória - foi o primeiro período do ensaio inicial, "Da violência":

Libertação nacional, renascimento nacional, restituição da nação ao povo, Commonwealth, sejam quais forem as cifras utilizadas ou as fórmulas novas que são introduzidas, a descolonização é sempre um fenómeno violento. (Fanon, 2002: 39)

Imediatamente, e de modo quase inevitável, o leitor pergunta a si próprio se esta é uma observação analítica ou uma recomendação política. E, evidentemente, a resposta pode ser que a ideia é que seja ambas as coisas. Talvez o próprio Fanon não esteja certo quanto a qual dos dois sentidos tem prioridade. E talvez isto, para ele, não importe. A reacção dos leitores a este ambíguo período inicial é, sem dúvida, mais função da psique do leitor do que da do autor. 
A ideia de que uma transformação social fundamental não ocorre nunca sem violência não era nova. Fazia parte das tradições emancipatórias radicais do século XIX. Estas acreditavam todas que os privilegiados nunca cedem poder real de bom grado e/ou voluntariamente; o poder é-lhes sempre arrancado. Esta crença constituía uma ampla parte daquilo que definia a diferença que se julgava existir entre uma via "reformista" e uma via "revolucionária" de transformação social. O problema é que, justamente no período pós-1945, a utilidade da distinção entre "revolução" e "reforma" estava a diluir-se - a diluir-se entre os próprios militantes dos movimentos mais impacientes, irados e intransigentes. E, em consequência, o uso da violência, não como análise sociológica, mas como recomendação política, estava a tornar-se problemático.

Se os movimentos "revolucionários", uma vez na posse do poder de Estado, pareciam levar a cabo muito menos transformações do que haviam prometido, não era menos verdade que os movimentos "reformistas", uma vez no poder, não faziam muito melhor. Daí a ambivalência a respeito da recomendação política. Os nacionalistas argelinos tinham vivido os seus próprios ciclos biográficos. Ferhat Abbas, o primeiro presidente do GPRA, tinha passado os primeiros trinta anos da sua vida política como reformista, acabando por admitir que ele e o seu movimento não tinham chegado a lado nenhum. Chegou à conclusão de que a insurreição violenta era a única táctica que fazia sentido se a Argélia não queria continuar a ser uma colónia para sempre, uma colónia "escravizada".

Fanon parece estar a defender essencialmente três teses sobre a violência como táctica política. Em primeiro lugar, no mundo colonial "maniqueísta”, a fonte original da violência encontra-se nos recorrentes actos violentos do colonizador:

Aquele a quem disseram constantemente que ele só compreendia a linguagem da força decide exprimir-se pela força. Na verdade, desde sempre o colono the apontou o caminho que deveria ser o seu, se quisesse libertar-se. $\mathrm{O}$ argumento escolhido pelo colonizado foi-lhe indicado pelo colono e, numa reviravolta irónica das coisas, é o colonizado que, agora, afirma que o colonizador só compreende a força. (Fanon, 2002: 81)

A segunda tese é que esta violência transforma a psicologia social, a cultura política, daqueles que foram colonizados.

Mas acontece que, para o povo colonizado, esta violência, pelo facto de constituir o seu único trabalho, reveste características positivas, formadoras. Esta práxis violenta é totalizante, uma vez que cada um se transforma em elo violento da grande 
cadeia, do grande organismo violento que surge como reacção à violência primeira do colonialista. Os grupos reconhecem-se entre si e a nação futura é já indivisa. A luta armada mobiliza o povo, isto é, lança-o numa só direcção de sentido único. (Fanon, 2002: 89-90)

A terceira tese, contudo, está no resto da obra e parece contradizer o tom extremamente optimista da segunda tese, o caminho aparentemente irreversível para a libertação nacional, a libertação humana. $\mathrm{Na}$ verdade, o segundo capítulo da obra intitula-se "Grandeza e fraqueza da espontaneidade" e o terceiro capítulo tem por título "Percalços da consciência nacional”. Estes capítulos são particularmente fascinantes à luz do primeiro capítulo sobre a violência, escritos como foram durante a guerra de libertação da Argélia que estava a decorrer.

O capítulo dois é uma crítica generalizada dos movimentos nacionalistas, cujo "vício congénito", diz Fanon, é

dirigir-se prioritariamente aos elementos mais conscientes: o proletariado das cidades, os artesãos e os funcionários, quer dizer, uma ínfima parte da população que não representa muito mais de um por cento [...]

Os partidos nacionalistas nutrem, na imensa maioria, uma grande desconfiança em relação às massas rurais. [...]

Os elementos ocidentalizados nutrem, em relação às massas camponesas, sentimentos que fazem lembrar os que encontramos no seio do proletariado dos países industrializados. (Fanon, 2002: 108-110)

Este vício congénito é, precisamente, o que os impede de serem movimentos revolucionários, que não podem basear-se no proletariado ocidentalizado, mas sim no campesinato recém-urbanizado e desenraizado:

É nesta massa, é neste povo dos bairros de lata, no seio do lumpenproletariado, que a insurreição vai encontrar a sua ponta de lança urbana. O lumpenproletariado, esta legião de esfomeados destribalizados, afastados do seu clã, constitui uma das forças mais espontânea e radicalmente revolucionárias de um povo colonizado. (Fanon, 2002: 125)

Fanon estava aqui obviamente influenciado pela batalha de Argel e pelo papel que esta desempenhou na revolução argelina. Ele passa deste hino ao lumpenproletariado destribalizado a uma análise da natureza dos movimentos nacionalistas uma vez chegados ao poder. É ferino e implacável e denuncia esses movimentos numa das mais famosas frases do seu livro: "O partido 
único é a forma moderna da ditadura burguesa sem máscara, sem disfarce, sem escrúpulos, cínica" (Fanon, 2002: 159). E diz o seguinte destes movimentos nacionalistas no poder em Estados de partido único:

As razões para combater a burguesia dos países subdesenvolvidos não consistem no risco de ela travar o desenvolvimento global e harmonioso da nação. Há que lhe fazer uma oposição resoluta porque, literalmente, ela não serve para nada. (Fanon, 2002: 168-169)

E, partindo daqui, Fanon passa para uma denúncia pura e simples do nacionalismo:

O nacionalismo não é uma doutrina política, não é um programa. Se se quer verdadeiramente evitar ao seu país estes retrocessos, estas paragens, estas falhas, é preciso passar rapidamente da consciência nacional à consciência política e social. [...] Uma burguesia que dá às massas o único alimento do nacionalismo fracassa na sua missão e sujeita-se necessariamente a uma série de percalços. (Fanon, 2002: 192-193)

O movimento de libertação nacional da Argélia, a Front de Libération Nationale (FLN), ainda não estava no poder. Fanon não estava ainda a criticá-la. Nunca saberemos o que poderia ter escrito dois anos depois, dez anos depois, podemos quando muito deduzi-lo.

É chegado a este ponto que Fanon se vira para questões de identidade, o meu segundo tema. Ele inicia a discussão dizendo que, como é evidente, gabar antigas civilizações não dá de comer a ninguém nos dias de hoje. Mas isso serve o propósito legítimo de tomar distâncias relativamente à cultura ocidental. A racialização da cultura foi, inicialmente, da responsabilidade dos colonizadores brancos:

É bem verdade que os grandes responsáveis por esta racialização do pensamento [...] são e continuam a ser os europeus, que nunca cessaram de opor a cultura branca às outras inculturas [...]. O conceito de negritude, por exemplo, era a antítese afectiva, ou mesmo lógica, deste insulto que o homem branco lançava à humanidade. (Fanon, 2002: 202-203)

Mas, diz Fanon:

Esta obrigação histórica de racializar as suas reivindicações em que se encontraram os homens de cultura africanos [...] vai conduzi-los a um impasse. (Fanon, 2002: 204) 
Na sua comunicação de 1959 ao II Congresso dos Escritores e Artistas Negros, reproduzido como capítulo 4, "Sobre a cultura nacional", Fanon é muito critico de qualquer tentativa de afirmar uma identidade cultural que seja independente da luta política pela libertação nacional ou não esteja inserida nela.

Imaginar que se irá fazer cultura negra é esquecer estranhamente que os negros estão em vias de desaparecer [...]. Não haverá cultura negra, porque a nenhum homem político passa pela cabeça ter a vocação de fazer nascer repúblicas negras. O problema é saber o lugar que estes homens têm a intenção de reservar ao seu povo, o tipo de relações sociais que decidem instaurar, a concepção que têm do futuro da humanidade. É isso que conta. Tudo o resto é literatura e mistificação. (Fanon, 2002: 222-223)

A sua tirada final está nos antípodas de uma política de identidade.

Se o homem é aquilo que faz, então diremos que a coisa hoje mais urgente para o intelectual africano é a construção da sua nação. Se esta construção é verdadeira, quer dizer, se ela traduz o querer manifesto do povo, se ela revela os povos africanos na sua impaciência, então a construção nacional é necessariamente acompanhada pela descoberta e a promoção de valores universalizantes. Longe, portanto, de se afastar das outras nações, é a libertação nacional que faz com que a nação esteja presente na cena histórica. É no cerne da consciência nacional que a consciência internacional se eleva e se vivifica. E este duplo emergir não é, em definitivo, senão a essência de toda a cultura. (Fanon, 2002: 235)

Mas depois, na sua Conclusão, como se tivesse exagerado na insuficiente afirmação dos méritos de uma via diferente para a África, uma via não-europeia, Fanon aponta o exemplo dos Estados Unidos, que tinham tomado por objectivo porem-se a par da Europa e tinham sido tão bem sucedidos que "se transformaram num monstro em que as taras, as doenças e a inumanidade da Europa atingiram dimensões aterradoras" (Fanon, 2002: 302). Para Fanon, assim, a África não deve tentar "pôr-se a par" da Europa, tornar-se uma terceira Europa. Muito pelo contrário:

A humanidade espera de nós uma coisa diferente desta imitação caricatural e, no conjunto, obscena.

Se queremos transformar a África numa nova Europa, a América numa nova Europa, então confiemos aos Europeus os destinos dos nossos países. Eles saberão fazer melhor do que os mais dotados de nós. 
Mas se queremos que a humanidade suba mais um furo, se queremos levá-la a atingir um nível diferente daquele em que a Europa a deu ao manifesto, então é preciso inventar, é preciso descobrir. [...]

Pela Europa, por nós próprios e pela humanidade, é preciso mudar de procedimentos, desenvolver um pensamento novo, tentar pôr de pé um homem novo. (Fanon, 2002: 304-305)

No percurso sinuoso de Fanon, em ambas as obras, em torno da questão da identidade cultural, da identidade nacional, encontramos o dilema fundamental que assolou todo o pensamento anti-sistémico no último meio século e, provavelmente, assolará também o meio século seguinte. A rejeição do universalismo europeu é fundamental para a rejeição do domínio pan-europeu e da sua retórica do poder na estrutura do sistema-mundo moderno, aquilo que Aníbal Quijano designou por colonialidade do poder. Mas, ao mesmíssimo tempo, todos aqueles que se comprometeram na luta por um mundo igualitário, naquilo a que pode chamar-se a aspiração socialista histórica, estão muito conscientes do que Fanon designou por os "percalços da consciência nacional". Por isso, o seu percurso é sinuoso. O percurso de todos nós é sinuoso. E continuará a sê-lo. Porque fazer um percurso sinuoso é a única forma de permanecer mais ou menos no caminho para um futuro em que, nas palavras de Fanon, "a humanidade sobe mais um furo".

E isto traz-nos então ao terceiro tema, a luta de classes. A luta de classes nunca é discutida de modo central enquanto tal em nenhum lugar das obras de Fanon. E, contudo, ela é central para a sua visão do mundo e as suas análises. É que, evidentemente, Fanon foi educado numa cultura marxista - na Martinica, em França, na Argélia. A linguagem que ele conhecia e a de todos com que trabalhava estava impregnada de premissas e de um vocabulário marxistas. Mas, ao mesmo tempo, Fanon e aqueles com quem trabalhava tinham-se rebelado, tinham-se rebelado vigorosamente, contra o marxismo fossilizado dos movimentos comunistas da sua época. O livro de Aimé Césaire, Discours sur le colonialisme, ficou como a expressão clássica das razões pelas quais os intelectuais do mundo colonial (e, evidentemente, não apenas eles) abandonaram o seu empenhamento nos partidos comunistas e afirmaram uma versão revista da luta de classes.

A questão chave dos debates sobre a luta de classes é a questão de saber quais são as classes que estão em luta. Durante muito tempo, o debate foi dominado pelas categorias do marxismo dos partidos - o Partido Social-Democrático Alemão e o Partido Comunista da União Soviética. A tese basilar era que, no mundo capitalista moderno, as duas classes que estavam 
empenhadas numa luta fundamental e dominavam a cena eram a burguesia industrial urbana e o proletariado industrial urbano. Todos os outros agrupamentos eram resíduos de estruturas mortas ou moribundas e estavam destinados a desaparecer, à medida que todos se iam fundindo, se iam definindo como burgueses e proletários.

$\mathrm{Na}$ altura em que Fanon estava a escrever, havia relativamente pouca gente a considerar isto uma síntese adequada ou mesmo fidedigna da situação real. Por um lado, o proletariado industrial urbano não apenas não estava sequer perto de se tornar a maioria da população mundial como, em geral, não parecia ser um grupo que não tivesse nada a perder a não ser as suas cadeias. Em resultado, a maioria dos movimentos e dos intelectuais estava à procura de um enquadramento diferente da luta de classes, um enquadramento mais bem ajustado enquanto análise sociológica e mais útil enquanto base de uma política radical. Havia muitas propostas de novos candidatos a sujeito histórico capaz de ser a ponta de lança da actividade revolucionária. Fanon julgava tê-lo localizado no lumpenproletariado destribalizado e urbanizado. Mas admitiu as suas dúvidas quando delineou as "fraquezas da espontaneidade".

No fim e ao cabo, o que nos resta de Fanon é mais do que paixão e mais do que um projecto de acção política. Temos um retrato brilhante dos nossos dilemas colectivos. Sem violência, não podemos conseguir nada. Mas a violência, por mais terapêutica e eficaz que seja, não resolve nada. Sem rompermos com a dominação pela cultura pan-europeia, não seremos capazes de ir em frente. Mas a afirmação pertinaz da nossa particularidade é absurda e conduz inevitavelmente a "percalços". A luta de classes é central, desde que saibamos quais são as classes que estão realmente em luta. Mas as classes lumpen, por si sós, sem uma estrutura organizativa, exaurem-se.

Encontramo-nos, como Fanon esperava, na longa transição do nosso sistema-mundo capitalista existente para uma outra coisa. Trata-se de uma luta cujo desfecho é completamente incerto. Fanon poderá não ter dito isso, mas as suas obras dão testemunho de que ele o pressentiu. A possibilidade de sairmos colectivamente desta luta e acabarmos num sistema-mundo melhor do que o que temos agora depende em larga medida da nossa capacidade para enfrentar os três dilemas discutidos por Fanon. Enfrentar estes dilemas e lidar com eles de um modo que seja, ao mesmo tempo, inteligente no plano analítico, moralmente empenhado na "désaliénation" por que Fanon lutou e politicamente adequado às realidades com que temos de confrontar-nos.

Tradução de António Sousa Ribeiro 
12 | Immanuel Wallerstein

\section{Referências bibliográficas}

Fanon, Frantz (1971), Peau noire, masques blancs. Paris: Seuil.

Fanon, Frantz (2002), Les damnés de la terre. Paris: La Découverte. 